\title{
Circulating microRNAs as novel biomarkers of ALK-positive non- small cell lung cancer and predictors of response to crizotinib therapy
}

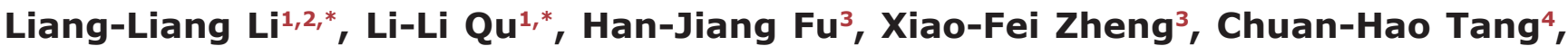 \\ Xiao-Yan Li ${ }^{1}$, Jian Chen ${ }^{5}$, Wei-Xia Wang ${ }^{1}$, Shao-Xing Yang ${ }^{1}$, Lin Wang ${ }^{1}$, Guan-Hua \\ Zhao $^{1}$, Pan-Pan Lv ${ }^{1}$, Min Zhang ${ }^{1}$, Yang-Yang Lei ${ }^{1}$, Hai-Feng Qin ${ }^{1}$, Hong Wang ${ }^{1}$, \\ Hong-Jun Gao ${ }^{1}$ and Xiao-Qing Liu ${ }^{1}$ \\ ${ }^{1}$ Department of Lung Cancer, Affiliated Hospital of Academy of Military Medical Sciences, Beijing, China \\ ${ }^{2}$ Department of Oncology, 309th Hospital of PLA, Beijing, China \\ ${ }^{3}$ Department of Biochemistry and Molecular Biology, Beijing Institute of Radiation Medicine, Beijing, China \\ ${ }^{4}$ Department of Oncology, Peking University International Hospital, Beijing, China \\ ${ }^{5}$ Department of Respiratory, Affiliated Hospital of Aviation Medicine, Beijing, China \\ *These authors contributed equally to this work and are co-first authors \\ Correspondence to: Xiao-Qing Liu, email: liuxq@medmail.com.cn
}

Keywords: microRNA, plasma, biomarker, non-small cell lung cancer, ALK

Received: January 26, 2017

Accepted: April 12, 2017

Published: April 30, 2017

Copyright: Li et al. This is an open-access article distributed under the terms of the Creative Commons Attribution License 3.0 (CC BY 3.0 ), which permits unrestricted use, distribution, and reproduction in any medium, provided the original author and source are credited.

\section{ABSTRACT}

Circulating microRNAs are potential diagnostic and predictive biomarkers, but have not been investigated for patients with anaplastic lymphoma kinase (ALK)-positive lung cancer. In this exploratory study, we sought to identify potential plasma biomarkers for ALK-positive non-small cell lung cancer (NSCLC). A microRNA microarray was used to select ALK-related microRNAs in ALK-positive NSCLC $(n=3)$, ALK-negative NSCLC $(n=3)$, and healthy subjects $(n=3)$. Plasma levels of 21 microRNAs were differentially expressed for ALK-positive and ALK-negative NSCLC, including 14 down-regulated and 7 up-regulated microRNAs. We also identified 5s rRNA as the most stable endogenous control gene using geNorm and NormFinder algorithms. Candidate microRNAs in plasma from ALK-positive $(n=41)$ and ALK-negative NSCLC patients $(n=32)$ were quantified using real-time reverse transcriptase quantitative polymerase chain reaction. The expression levels of miR-28-5p, miR-362-5p, and miR-660-5p were all down-regulated in ALK-positive NSCLC, compared with ALK-negative NSCLC. The areas under the receiver operating characteristic curves of miR-28-5p, miR-362-5p, miR-660-5p, and 3-microRNAs panel were $0.873,0.673,0.760$, and 0.876 , respectively. The positive predictive values of miR-28-5p, miR-362-5p, and miR-660-5p were $96.43 \%, 80.77 \%$, and $\mathbf{8 3 . 8 7 \%}$, respectively. Increased plasma levels of miR-660-5p after crizotinib treatment predicted good tumor response $(p=0.012)$. The pre-crizotinib levels of miR-362-5p were significantly associated with progression-free survival $(p=0.015)$. Thus, in this preliminary investigation, we identified a potential panel of 3 microRNAs for distinguishing between patients with ALK-positive and ALK-negative NSCLC. We also identified miR-660-5p and $\mathrm{miR}-362-5 p$ as potential predictors for response to crizotinib treatment.

\section{INTRODUCTION}

In 2007, investigators in Japan identified anaplastic lymphoma kinase (ALK) as a novel potential target in NSCLC. ALK rearrangements occur in $3 \%$ to $7 \%$ of patients with NSCLC. Most ALK-positive lung cancer patients are characterized by younger ages, no history of smoking or a history of light smoking, and adenocarcinoma histology [1,2]. Patients who have advanced ALK-positive NSCLC are highly responsive to 
the ALK inhibitor crizotinib, with an objective response rate of approximately $60 \%$ and a median progression-free survival of 8 to 10 months $[3,4]$. The current standard method for detecting ALK-positivity in NSCLC is fluorescence in situ hybridization (FISH) [5]. However, it is sometimes difficult to collect tumor tissues from patients with advanced-stage NSCLC. It has been shown that circulating biomarkers are present in plasma and other body fluids, and may have potential as novel, non-invasive biomarkers [6-8]. Recent findings indicate that circulating microRNAs are useful as non-invasive biomarkers for different tumor types, including lung cancer [9-16].

MicroRNAs are a class of evolutionarily conserved, small (18 to 24 nucleotides), non-coding RNA molecules that play key roles in the regulation of gene expression by base pairing to the complementary sites in their target mRNAs [17-19]. Increasing evidence has shown that microRNAs have more important roles in tumor development than had previously been anticipated; specifically, they are believed to act as tumor suppressors or oncogenes in a wide range of human cancers [20-22].

In the past decade, it was found that microRNAs are stably expressed in human blood, and that circulating microRNAs may serve as disease fingerprints and novel molecular biomarkers for cancer [23, 24]. Blood-based biomarkers have several significant advantages: they can be obtained easily and in a minimally invasive manner, they can be measured repeatedly, and they can be compared longitudinally. However, circulating microRNAs in plasma have not been systematically and extensively studied in ALK-positive lung cancer. Therefore, in this exploratory study, we sought to identify a plasma microRNA panel that could effectively separate ALK-positive NSCLC patients from ALK-negative individuals. Furthermore, we sought to explore the potential of the microRNA panel as a noninvasive predictive biomarker for response to crizotinib.

\section{RESULTS}

\section{Clinical characteristics}

A total of 73 participants, including 41 patients with ALK-positive lung cancer and 32 patients with ALKnegative lung cancer, were enrolled in the validation phase of the present study. The overall study design is shown in Figure 1. The clinical features of the participants are listed in Table 1. There were no significant differences in gender, clinical stage, or pathology between the patients with ALKpositive and ALK-negative disease. However, there were significant differences in clinical characteristics such as age and smoking history. Compared with ALK-negative NSCLC patients, ALK-positive NSCLC patients tended to be younger and have little or no smoking histories. The median ages of patients with ALK-positive and ALK-negative NSCLC were 50 years (range, 28-69) and 61.4 yeas (range, 34-84), respectively. The proportion of never-smokers in the
ALK-positive group was significantly higher than that in the ALK-negative group (68.3\% vs. $43.8 \%$ ).

\section{Selection of differential microRNAs by microarray}

In our investigation, circulating microRNAs from plasma samples of patients with ALK-positive NSCLC $(n=3)$, patients with ALK-negative NSCLC $(n=3)$, and healthy subjects $(n=3)$ were analyzed by microarray (Human miRNA Microarray, G4872A; Agilent Technologies, Santa Clara, CA, USA; Gene Expression Omnibus accession no. GSE94536) and real-time reverse transcriptase quantitative polymerase chain reaction (RT-qPCR) technologies. Among the 2,568 microRNAs assessed with the microarray technology, 438 microRNAs were detected in at least 1 out of the 9 samples analyzed. It is worth noting that the total numbers of circulating microRNAs differed in the 3 cohorts. Compared with the cohorts of patients with NSCLC, more microRNAs were detected in the plasma of healthy subjects. Specifically, 409 microRNAs were detected in healthy subjects, whereas 116 were detected in patients with ALK-positive NSCLC and 209 were detected in patients with ALKnegative NSCLC (Figure 2).

We identified 21 microRNAs that were differentially expressed in plasma between patients with ALK-positive NSCLC and those with ALK-negative NSCLC. Compared with the ALK-negative group, plasma from the ALKpositive group had 7 up-regulated microRNAs and 14 down-regulated microRNAs (fold change $>2$ or $<0.5$ ) (Table 2).

\section{Identification of the endogenous control genes}

As shown in Figure 3, the geNorm and NormFinder algorithms were used to rank the candidate reference genes according to their expression stability. Based on calculations performed with geNorm, 5s rRNA had the most stable expression level and thus was selected as the endogenous control gene. NormFinder confirmed the results that had been obtained by geNorm, showing that $5 \mathrm{~s}$ rRNA was the most stable reference gene. Several other genes that are commonly used as reference genes for microRNA RT-qPCR experiments ranked behind 5s rRNA, suggesting that they should not be considered suitable reference genes for this study. These genes included $18 \mathrm{~s}$ rRNA, RNU6B, RNU38B, RNU44, RNU43, RNU48, miR-221-3p, miR-93-5p, miR-191-5p, miR-103-3p, and miR-197-3p.

\section{Selection of candidate plasma microRNAs for ALK-positive NSCLC}

According to microarray analysis, the levels of 21 microRNAs were differentially expressed between 
Table 1: Patient characteristics at the time of primary diagnosis

\begin{tabular}{|c|c|c|c|}
\hline Clinical variable & $\begin{array}{l}\text { ALK-positive } \\
\text { NSCLC } \\
(n=41)\end{array}$ & $\begin{array}{l}\text { ALK-negative } \\
\text { NSCLC } \\
(n=32)\end{array}$ & $p$ value \\
\hline Age & & & 0.002 \\
\hline Median (range) & $50.0(28-69)$ & $61.4(34-84)$ & \\
\hline Gender & & & 0.526 \\
\hline Male & $20(48.8 \%)$ & $18(56.3 \%)$ & \\
\hline Female & $21(51.2 \%)$ & $14(43.8 \%)$ & \\
\hline Stage & & & 0.194 \\
\hline III & $4(9.8 \%)$ & $7(21.9 \%)$ & \\
\hline IV & $37(90.2 \%)$ & $25(78.1 \%)$ & \\
\hline Smoking history & & & 0.043 \\
\hline Never smokers & $28(68.3 \%)$ & $14(43.8 \%)$ & \\
\hline Light smokers (smoking pack-years $<30$ ) & $9(22.0 \%)$ & $8(25.0 \%)$ & \\
\hline Heavy smokers (smoking pack-years $\geq 30$ ) & $4(9.8 \%)$ & $10(31.3 \%)$ & \\
\hline Histologic subtype & & & 0.189 \\
\hline Adenocarcinoma & $41(100 \%)$ & $30(93.8 \%)$ & \\
\hline Squamous carcinoma & 0 & 0 & \\
\hline Others & 0 & $2(6.3 \%)$ & \\
\hline Differentiation & & & 0.587 \\
\hline G1 & 0 & 0 & \\
\hline G2 & $3(7.3 \%)$ & $3(9.4 \%)$ & \\
\hline G3 & $19(46.3 \%)$ & $11(34.4 \%)$ & \\
\hline Gx & $19(46.3 \%)$ & $18(56.3 \%)$ & \\
\hline
\end{tabular}

ALK, anaplastic lymphoma kinase; NSCLC, non-small cell lung cancer. G1: low grade or well differentiated cancer cells, which still closely resemble normal cells; G2: intermediate/moderate grade or moderately differentiated cancer cells, which do not look like normal cells; G3: high grade or poorly differentiated cancer cells, which do not look like normal cells at all; Gx: grade unknown.

patients with ALK-positive and ALK-negative NSCLC. Of these differentially expressed microRNAs, 14 were down-regulated and 7 were up-regulated in ALK-positive NSCLC, as compared with ALK-negative NSCLC (Table 2). To increase the likelihood of identifying useful plasma biomarkers, we focused on the microRNAs that showed the highest degrees of dysregulation in the ALKpositive NSCLC samples (fold-change in comparison to ALK-negative NSCLC) and that were among the most abundant in terms of absolute expression levels. In addition, we searched the published literature for microarray data on ALK-positive and ALK-negative NSCLC tissue [25]. Inconsistent expression levels between plasma samples and tissue samples were observed. Comparing our plasma microarray data with the tissue microarray data based on the published literature, 2 microRNAs (miR-362-5p and miR-579-5p) with high expression differences in tissue microarray findings were added.

Based on these criteria, we selected 13 microRNAs for further analysis in plasma by RT-qPCR: miR-16-5p,
miR-17-5p, miR-19a-3p, miR-20a-5p, miR-22-3p, miR362-5p, miR-24-3p, miR-28-5p, miR-96-5p, miR-107, miR-340-5p, miR-579-5p, and miR-660-5p. The primers are listed in Table 3.

\section{Validation of candidate microRNAs by RT-qPCR}

The 13 microRNAs selected from the microarray results were first confirmed in the validation cohort, which included 41 ALK-positive NSCLC cases and 32 ALKnegative NSCLC cases. Only the microRNAs with a mean fold change $>2$ or $<0.5$ and a $p$ value $<0.5$ were selected for further validation. Three of the 13 microRNAs were markedly dysregulated in plasma according to ALK status. These 3 microRNAs, miR-28-5p, miR-362-5p, and miR$660-5 p$, were all down-regulated (Figure 4).

Subsequently, we conducted receiver operating characteristic (ROC) curve analyses on each of the 3 individual plasma microRNAs, to assess their diagnosis values for distinguishing between patients with ALK- 
positive and ALK-negative NSCLC. To determine whether the plasma levels of miR-28-5p, miR-362-5p, and miR660-5p had the abilities to discriminate between the ALKpositive and ALK-negative groups, ROC curves were used to estimate their diagnostic sensitivities and specificities (Figure 5; Table 4).

Based on an optimal cut-off value $(-1.493)$ that was chosen using Youden's Index, the sensitivity and specificity of miR-28-5p were $65.85 \%$ and $96.88 \%$ for distinguishing patients with ALK-positive NSCLC from those with ALK-negative NSCLC (area under curve $[\mathrm{AUC}]=0.873,95 \% \mathrm{CI}, 0.795-0.952)$. With a threshold of -1.984 (AUC $=0.673,95 \%$ CI, 0.549-0.796), and the sensitivity and specificity of miR-362-5p were $51.22 \%$ and $84.38 \%$. With a threshold of 0.7902 , the sensitivity and specificity of miR-660-5p were $63.41 \%$ and $84.38 \%$

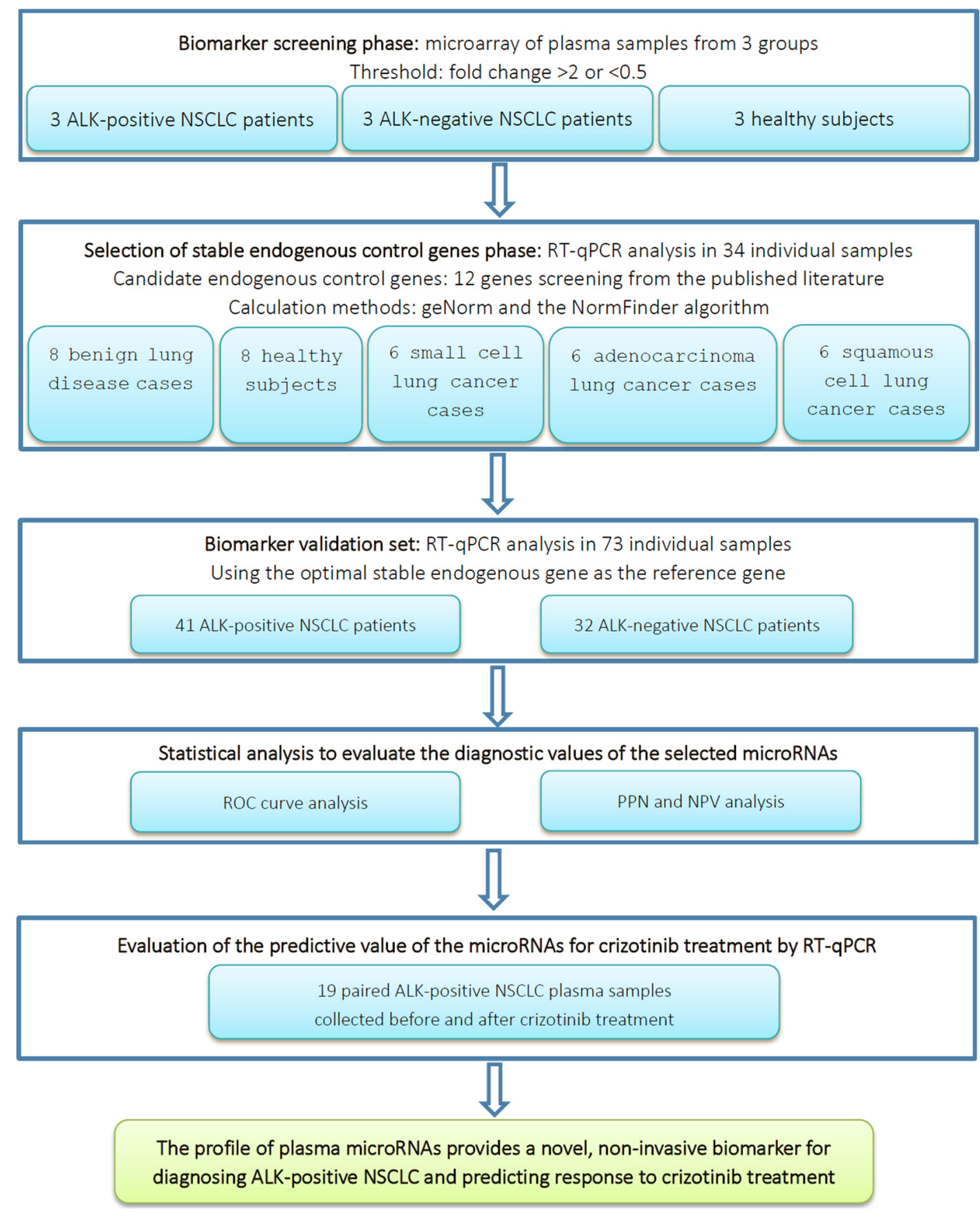

Figure 1: Overall study design and numbers of included patients. ALK, anaplastic lymphoma kinase; NPV, negative predictive value; NSCLC, non-small cell lung cancer; PPV, positive predictive value; ROC, receiver operating characteristic curve; RT-qPCR, realtime quantitative polymerase chain reaction. 
Table 2: MicroRNAs that were found to be dysregulated between patients with ALK-positive and ALK-negative non-small cell lung cancer, based on microarray analysis

\begin{tabular}{rcccc}
\hline \multirow{2}{*}{$\boldsymbol{N}$} & Systematic name & \multicolumn{3}{c}{ ALK-pos vs. ALK-neg } \\
\cline { 3 - 5 } & miR-16-5p & Regulation & FC & $\boldsymbol{p}$ value \\
\hline 1 & miR-17-5p & down & 9.44 & 0.246 \\
2 & down & 12.33 & 0.009 \\
3 & miR-19a-3p & down & 27.72 & 0.002 \\
4 & miR-20a-5p & down & 31.06 & 0.002 \\
5 & miR-22-3p & down & 9.42 & 0.123 \\
6 & miR-24-3p & down & 32.86 & 0.008 \\
7 & miR-25-3p & down & 36.01 & 0.002 \\
8 & miR-28-5p & down & 14.87 & 0.005 \\
9 & miR-96-5p & down & 10.55 & 0.020 \\
10 & miR-107 & down & 30.23 & 0.002 \\
11 & miR-340-5p & down & 2.89 & 0.060 \\
12 & miR-483-3p & up & 30.196 & 0.038 \\
13 & miR-579-5p & up & 2.50 & 0.034 \\
14 & miR-619-5p & up & 10.93 & 0.021 \\
15 & miR-660-5p & down & 34.51 & 0.006 \\
16 & miR-3195 & down & 8.45 & 0.038 \\
17 & miR-4306 & down & 42.59 & 0.001 \\
18 & miR-6751-3p & up & 32.86 & 0.046 \\
19 & miR-6779-3p & up & 14.34 & 0.021 \\
20 & miR-6797-3p & up & 17.38 & 0.030 \\
21 & miR-6858-5p & up & 30.03 & 0.037 \\
\hline
\end{tabular}

ALK, anaplastic lymphoma kinase; ALK-pos, ALK-positive; ALK-neg, ALK-negative; FC, fold change.

$(\mathrm{AUC}=0.760,95 \% \mathrm{CI}, 0.649-0.870)$. Furthermore, combining the 3 microRNAs increased the AUC $(0.876$, 95\% CI, 0.801-0.951) and specificity (96.88\%), but decreased the sensitivity (63.41\%) for distinguishing between the ALK-positive and ALK-negative groups.

To clarify the diagnostic capability of the combination of the 3 microRNAs, we also estimated the positive predictive value (PPV) and negative predictive value (NPV) for distinguishing ALK-positive patients from ALK-negative patients. As shown in Table 4, the PPV for the 3 microRNAs was higher than $80 \%$, which indicated that a non-small cell lung cancer patient with low plasma levels of any 1 of the 3 microRNAs was more likely to have ALK-positive disease compared with a patient with high plasma levels of the 3 microRNAs. In addition, the NPV of the 3 microRNAs was higher than $64 \%$. Overall, the results indicate that the plasma levels of the 3 microRNAs have high diagnostic value.

\section{The changes in plasma levels of miR-660-5p after crizotinib treatment predict tumor response}

To determine whether the plasma levels of miR$28-5 p$, miR-362-5p, and miR-660-5p had predictive value for response to crizotinib therapy, the plasma levels of the 3 microRNAs in 19 patients were compared before and after crizotinib treatment using RT-qPCR. Fifty-seven plasma samples were collected from the 19 patients at time points before and after treatment with crizotinib. The blood samples were collected for the first time 2 weeks ( \pm 2 days) before crizotinib and then every 2 months ( \pm 1 week) thereafter. At the same times, chest computed tomography was performed to evaluate response to therapy. Of the 19 patients, 16 had a partial response and 3 had progressive disease. Pre- and posttreatment microRNA levels are shown in Figure 6, and were analyzed using the Wilcoxon matched pairs signed rank sum test. The plasma levels of miR-660-5p increased after crizotinib treatment in $15(93.75 \%)$ of the 16 patients with partial response $(p=0.001)$. In contrast, a similar trend was not observed in the remainder of the patients, who had progressive disease. The plasma level changes of miR-28-5p and miR-362-5p after crizotinib treatment were not statistically significant $(p=0.776$ and $p=0.796$, respectively). Overall, our investigation of the 3 microRNAs showed that changes in the plasma level of miR-660-5p before and after crizotinib treatment had value as a predictor of good tumor response. 


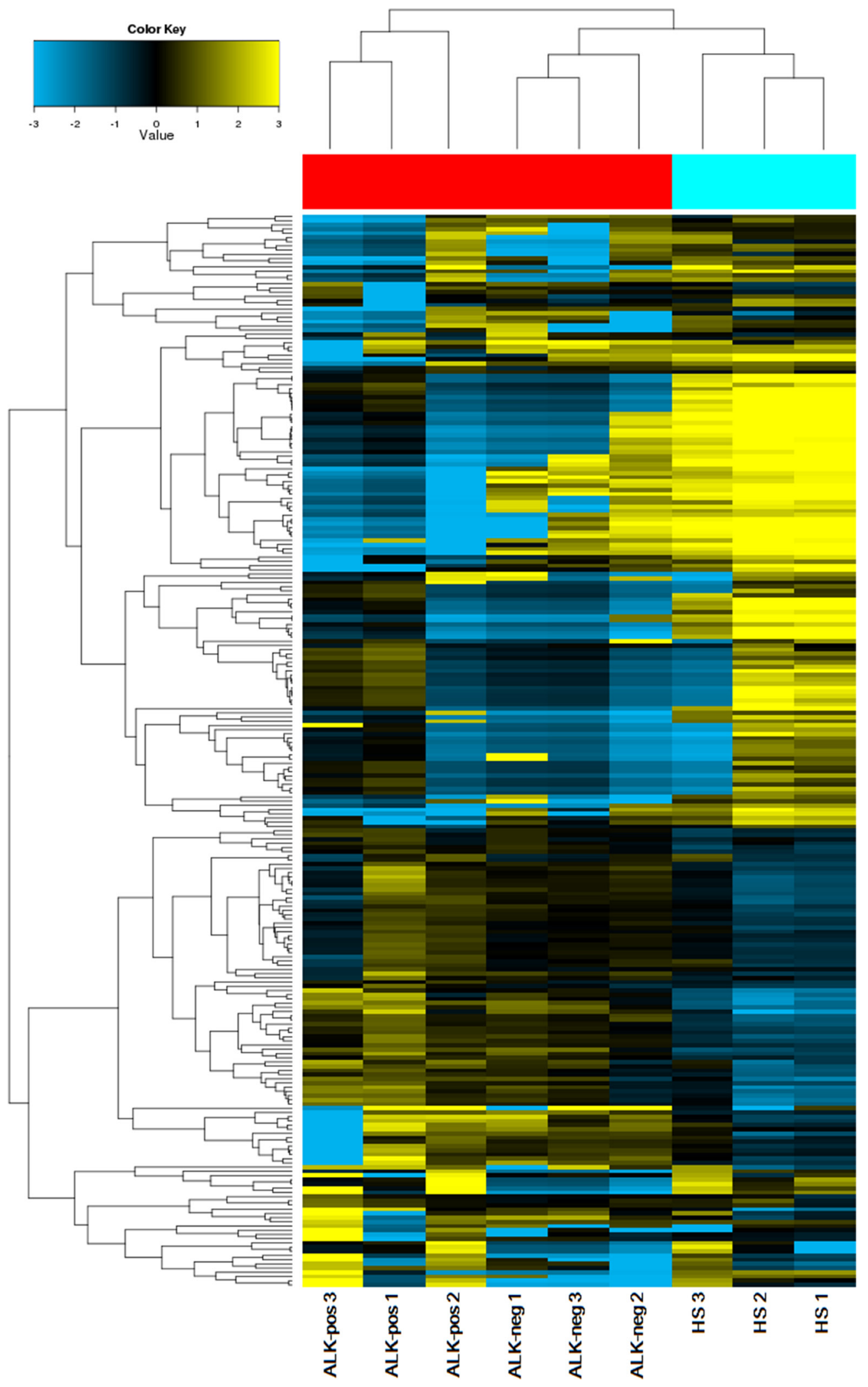

Figure 2: Cluster analysis of microRNA expression profiles in plasma from ALK-positive NSCLC, ALK-negative NSCLC, and HS cohorts. 


\begin{tabular}{|c|c|}
\hline MicroRNA & Primer sequence $\left(5^{\prime}\right.$ to $\left.3^{\prime}\right)$ \\
\hline 5s rRNA Forward & TCTGATCTCGGAAGCTAAGCA \\
\hline 5s rRNA Reverse & CCTACAGCACCCGGTATTCC \\
\hline miR-16-5p & TAGCAGCACGTAAATATTGGCG \\
\hline $\operatorname{miR}-17-5 p$ & CAAAGTGCTTACAGTGCAGGTAG \\
\hline $\operatorname{miR}-19 a-3 p$ & TGTGCAAATCTATGCAAAACTGA \\
\hline $\operatorname{miR}-20 a-5 p$ & TAAAGTGCTTATAGTGCAGGTAG \\
\hline miR-22-3p & AAGCTGCCAGTTGAAGAACTGT \\
\hline $\operatorname{miR}-24-3 p$ & TGGCTCAGTTCAGCAGGAACAG \\
\hline miR-28-5p & AAGGAGCTCACAGTCTATTGAG \\
\hline miR-96-5p & TTTGGCACTAGCACATTTTTGCT \\
\hline miR-107 & AGCAGCATTGTACAGGGCTATCA \\
\hline $\operatorname{miR}-340-5 p$ & TTATAAAGCAATGAGACTGATT \\
\hline $\operatorname{miR}-362-5 p$ & AATCCTTGGAACCTAGGTGTGAGT \\
\hline $\operatorname{miR}-579-5 p$ & TCGCGGTTTGTGCCAGATGACG \\
\hline miR-660-5p & TACCCATTGCATATCGGAGTTG \\
\hline
\end{tabular}

Table 4: Measures of diagnostic performance for distinguishing patients with ALK-positive and ALK-negative non-small cell lung cancer

\begin{tabular}{lccc}
\hline \multicolumn{1}{c}{ Variables } & miR-28-5p & miR-362-5p & miR-660-5p \\
\hline Cut-off & -1.493 & -1.984 & 0.7902 \\
Sensitivity & $65.85 \%$ & $51.22 \%$ & $63.41 \%$ \\
Specificity & $96.88 \%$ & $84.38 \%$ & $84.38 \%$ \\
PPV & $96.43 \%$ & $80.77 \%$ & $83.87 \%$ \\
NPV & $68.89 \%$ & $57.45 \%$ & $64.29 \%$ \\
\hline
\end{tabular}

ALK, anaplastic lymphoma kinase; PPV, positive predictive value; NPV, negative predictive value.

The relationship between the initial plasma levels of microRNAs and the progression-free survival of patients treated with crizotinib

Of 41 patients with ALK-positive NSCLC, 31 received crizotinib therapy. We performed KaplanMeier analyses of progression-free survival (PFS) for clinicopathological factors and the initial (pre-crizotinib) plasma levels of miR-28-5p, miR-362-5p, and miR-660-5p. Because 30 of the 31 patients had a performance status of 1 , and only 1 patient had a performance status of 0 , performance status was excluded from the Kaplan-Meier analyses. The expression levels of the 3 microRNAs in plasma were first stratified by their median values. Next, the PFS of the patients with high microRNA expression levels ( $\geq$ median) was compared with the PFS of patients with low microRNA expression levels ( $<$ median). As shown in Figure 7, the median PFS of the 31 patients was 6 months (range, 1-28). The initial expression levels of miR-28-5p and miR-660-5p had no significant association with PFS ( $p=0.712$ and $p=0.7686$, respectively). However, the expression levels of miR-362-5p were significantly associated with PFS $(p=0.015)$, showing the predictive value. For patients with high and low expression levels of miR-362-5p, the median PFS times were 18 and 6 months, respectively (hazard ratio, $0.285 ; 95 \%$ confidence interval, 0.104-0.780), respectively. As shown in Table 5, smoking history was significantly associated with PFS (hazard ratio, 0.01; 95\% confidence interval, 0.00-0.06; $p=0.001)$. These results suggest that miR-362-5p and smoking history were both important predictive factors for ALK-positive NSCLC patients receiving crizotinib therapy. Next, a multivariate analysis was performed, including all of the factors that showed significant associations with PFS in the Kaplan-Meier analyses. Clinical stage was also included, considering its correlation with survival. In the multivariate analysis, lower expression of miR-362-5p was significantly associated with longer PFS. However, smoking history and stage were not independent prognostic factors for PFS (Table 6). 


\section{DISCUSSION}

In this study, we evaluated the potential of circulating microRNAs as novel biomarkers of ALK status and response to crizotinib in patients with NSCLC.

To our knowledge, our report is the first to describe a prospective analysis of circulating microRNAs as diagnostic or prognostic biomarkers for ALK-positive lung cancer that is treated with crizotinib. We identified a new panel of 3 microRNAs (miR-28-5p, miR-362-5p, and miR-660-5p) that can distinguish ALK-positive NSCLC from ALK-negative NSCLC with high specificity and sensitivity. The plasma levels of the 3 microRNAs were all down-regulated in ALK-positive NSCLC patients, as compared with ALK-negative NSCLC patients. For each of the 3 microRNAs, the PPV exceeded $80 \%$.

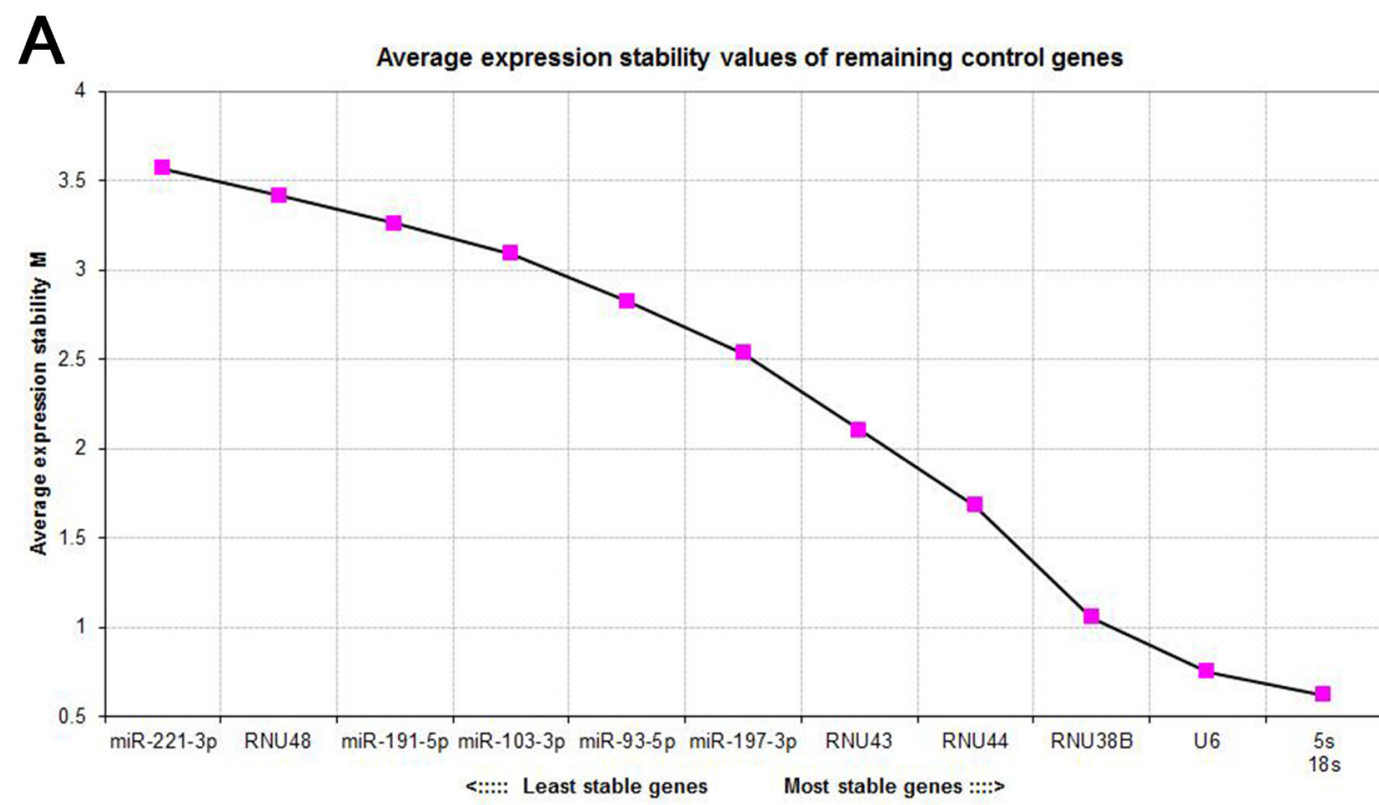

B

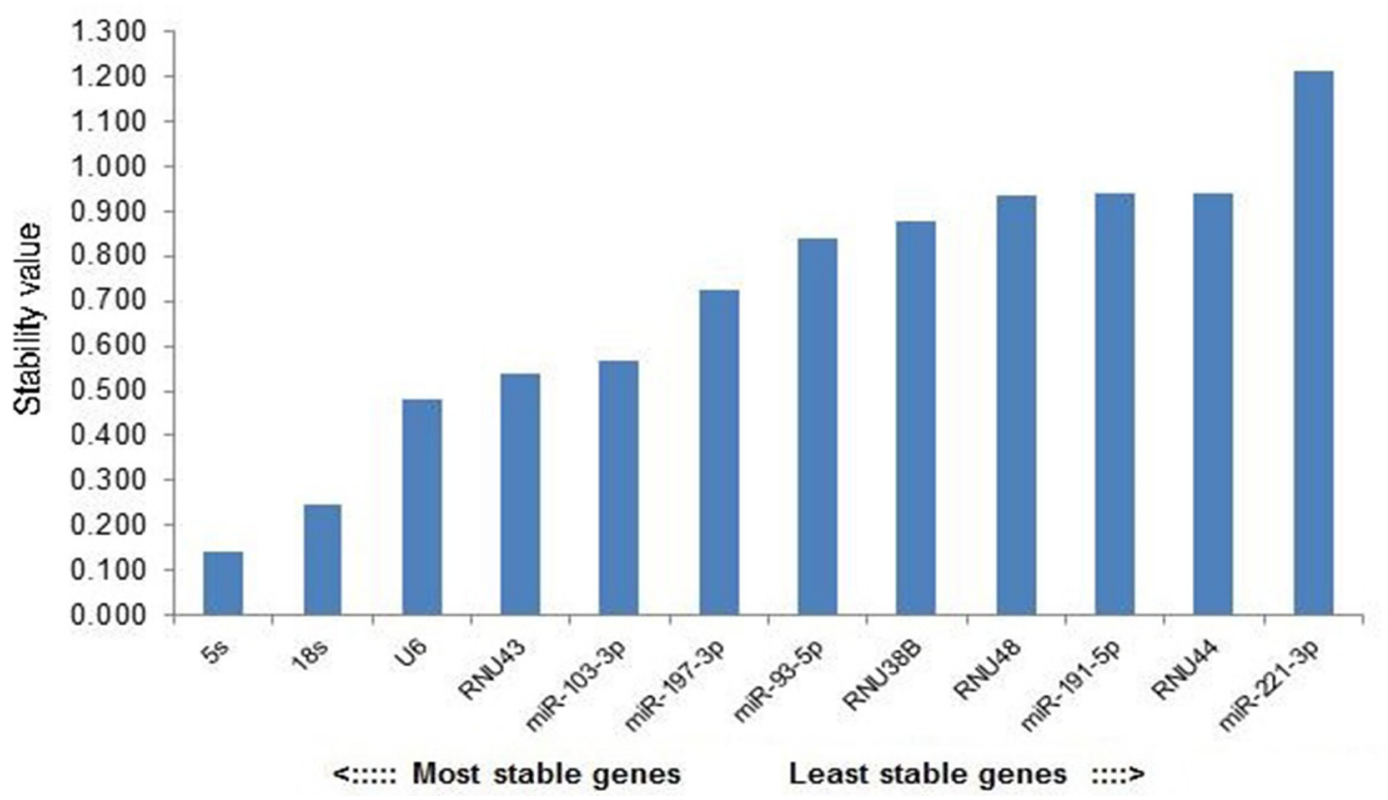

Figure 3: The stability of candidate endogenous genes was ranked using geNorm and the NormFinder algorithm. (A) Selection of the most stable reference genes from a panel of 12 genes using geNorm. The geNorm program calculated the average expression stability value (M) for each gene. Starting from the least stable genes at the left, the genes were ranked according to increasing expression stability, ending with the 2 most stable genes at the right. Candidates $5 \mathrm{~s}$ and $18 \mathrm{~s}$ were the 2 most stable genes. (B) Identification of the most stable reference gene or gene combination using NormFinder. The NormFinder algorithm ranks the set of candidate normalization genes according to their expression stability in different groups. When using this algorithm, greater gene stability is indicated by a lower stability value for the individual gene. Candidate $5 \mathrm{~s}$ was the most stable gene. 
Table 5: Kaplan-Meier analysis of factors associated with progression-free survival

\begin{tabular}{lcc}
\hline \multicolumn{1}{c}{ Clinical variables } & Hazard ratio (95\% CI) & $\boldsymbol{p}$ value \\
\hline Gender (male vs. female) & $1.88(0.75-4.70)$ & 0.177 \\
Age ( $\geq$ 60 years vs. $<60$ years) & $0.71(0.27-1.86)$ & 0.485 \\
Stage (IIIB vs. IV) & $0.58(0.17-1.96)$ & 0.379 \\
Smoking history (pack-years <30 vs. pack-years $\geq 30)$ & $0.01(0.00-0.06)$ & 0.001 \\
Differentiation (G2 vs. G3) & $1.33(0.12-14.28)$ & 0.813 \\
miR-28-5p (low-expression vs. high-expression ) & $0.84(0.34-2.10)$ & 0.712 \\
miR-362-5p (low-expression vs. high-expression ) & $0.29(0.10-0.78)$ & 0.015 \\
miR-660-5p (low-expression vs. high-expression ) & $0.87(0.36-2.14)$ & 0.769 \\
\hline
\end{tabular}

CI, confidence interval; G2, intermediate/moderate grade; G3, high grade.

Progression-free survival was analyzed using the Kaplan-Meier method, and Hazard ratios were estimated using the Logrank test.

Table 6: Multivariate analysis of factors associated with progression-free survival

\begin{tabular}{lcc}
\hline \multicolumn{1}{c}{ Clinical variables } & \multicolumn{2}{c}{ Progression-free survival } \\
\cline { 2 - 3 } & Hazard ratio (95\% CI) & $\boldsymbol{p}$ value \\
\hline Stage (IV vs. IIIB) & $1.85(0.42-8.18)$ & 0.419 \\
Smoking history (pack-years $\geq 30$ vs. pack-years $<30)$ & $5.96(0.97-36.68)$ & 0.054 \\
miR-362-5p (low-expression vs. high-expression) & $0.32(0.12-0.88)$ & 0.027 \\
\hline
\end{tabular}

CI, confidence interval.

Hazard ratios were estimated using the multivariate Cox proportional regression hazards model.

Furthermore, increased plasma levels of miR-660-5p after treatment with crizotinib were correlated with good tumor response in patients who had ALK-positive NSCLC. Our results suggest that this panel of 3 microRNAs has considerable potential as an auxiliary diagnostic, and that dynamic monitoring of microRNA biomarkers could be useful for ALK-positive NSCLC patients receiving crizotinib treatment.

In previous studies of NSCLC, several different reference control genes were reported, including small RNAs, endogenous microRNAs, and external non-human microRNAs. At present, there is no known, optimal, stable
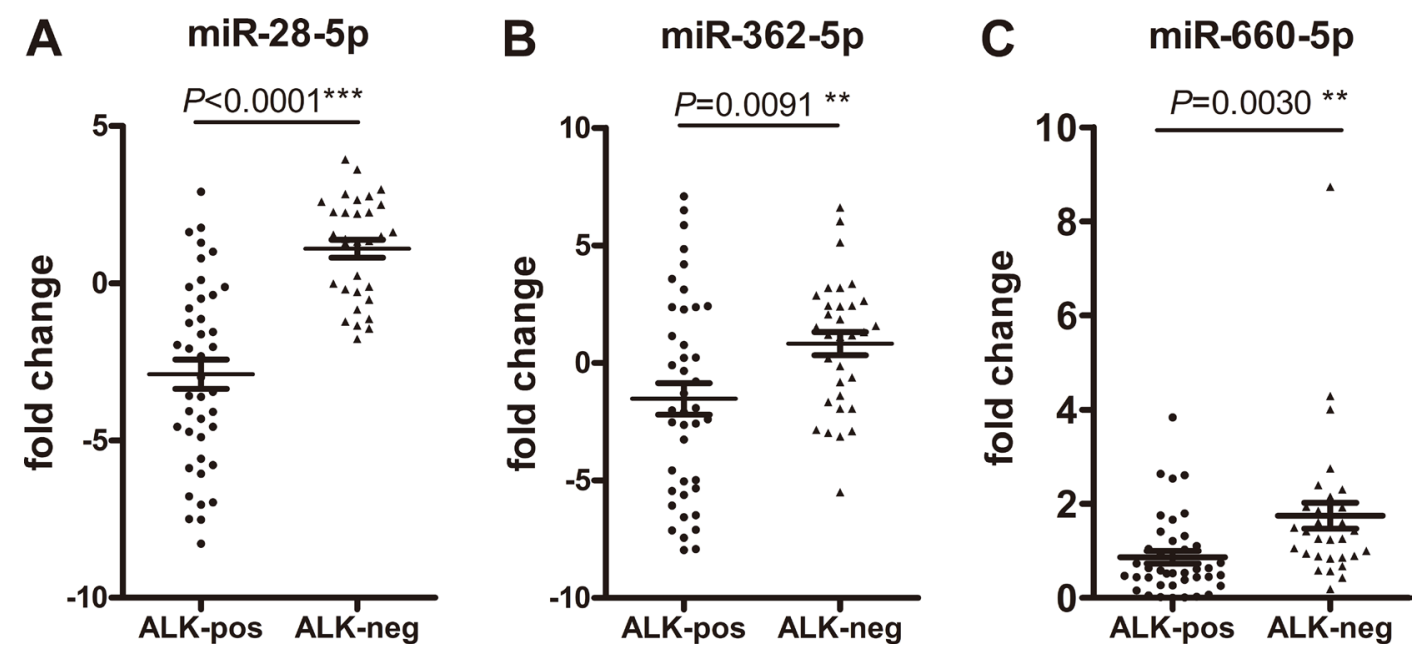

Figure 4: Plasma levels of miR-28-5p, miR-362-5p, and miR-660-5p are reduced in patients with anaplastic lymphoma kinase (ALK)-positive non-small cell lung cancer. The microRNA expression levels in the ALK-positive and ALK-negative nonsmall cell lung cancer cohorts ( $\mathrm{x}$-axis) are shown as $2^{-\Delta \Delta \mathrm{Ct}}$ values (y-axis), as calculated from real-time quantitative polymerase chain reaction. Statistically significant $p$ values are indicated as follows: ${ }^{*} p<0.05 ; * *<0.01 ; * * * p<0.001$. 
endogenous control gene in the plasma of patients with NSCLC. In the present study, 12 candidate reference genes were analyzed using the geNorm and NormFinder algorithms. These algorithms confirmed that $5 \mathrm{~s}$ rRNA was the most stable endogenous control gene in the cohorts of patients with lung cancer, patients with benign lung diseases, and health subjects. The use of this appropriate reference for the normalization of microRNAs in plasma improves the sensitivity and reproducibility of the results and helps to ensure reliable biomarker discovery.

To date, no report has described correlations between miR-28-5p and lung cancer or the ALK pathway. Research on expression levels of miR-28-5p in other cancers has shown inconsistent results [26-34]. Most of these prior reports have demonstrated that miR-28-5p is down-regulated in cancer tissue or blood. However, another report noted that miR-28 is stable in esophageal cancer tissue, and can be used as internal reference gene [26]. In our study, plasma levels of miR-28-5p were downregulated in ALK-positive NSCLC patients, as compared with ALK-negative NSCLC patients.
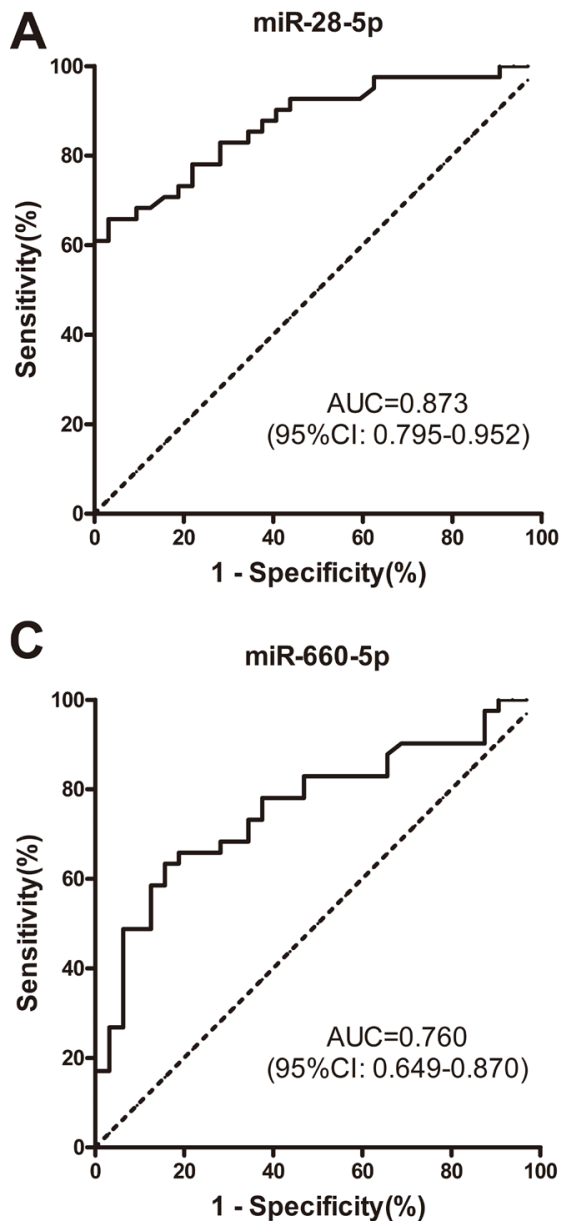

Although we performed a search of the literature, we did not find any studies that investigated the associations between miR-362-5p and ALK-positivity in patients with lung cancer. However, in studies of neuroblastoma and gestational diabetes mellitus, miR-362-5p was found to be involved in the PI3K pathway $[35,36]$. As is commonly known, PI3K is a downstream signaling pathway of the ALK pathway. Therefore, miR-362-5p may be associated with ALK status through signal transducer and activator of transcription (STAT).

We know little about the role of miR-660-5p in tumors. Some studies have shown that miR-660 is a prognostic marker in breast cancer [37], and is also downregulated in Hodgkin's lymphoma [38]. In the present study, miR-660-5p was decreased in patients with ALKpositive NSCLC. MiR-660-5p can not only be used as a diagnostic marker for ALK-positive lung cancer, but is also associated with the efficacy of crizotinib.

There are several limitations to this study. First, the participant samples were collected from a single lung cancer center. Further external validation of our results

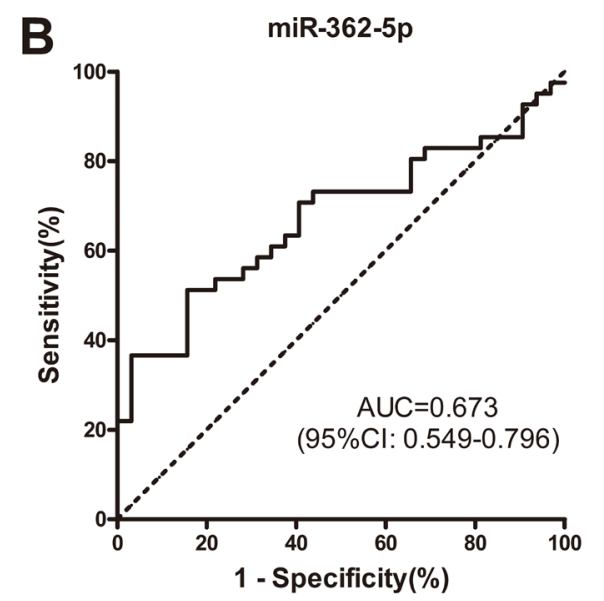

D

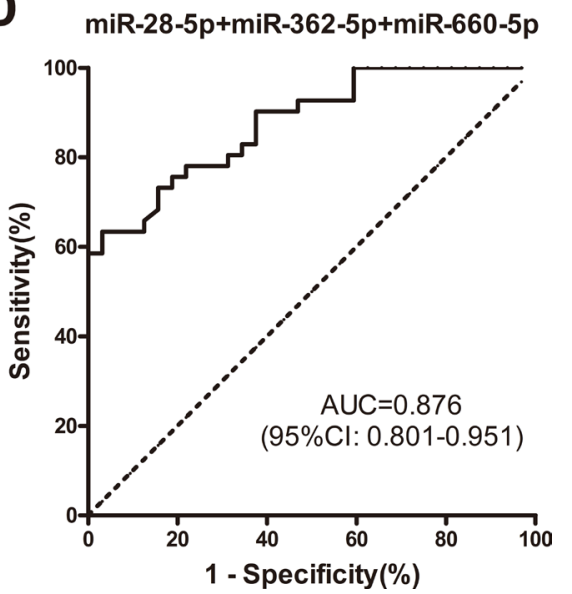

Figure 5: ROC curve analyses demonstrated that plasma levels of miR-28-5p, miR-362-5p, and miR-660-5p differed between patients with ALK-positive and ALK-negative NSCLC. (A-C) ROC curves showing that plasma levels of miR-28-5p, miR-362-5p, and miR-660-5p differ between patients with ALK-positive and ALK-negative NSCLC. (D) Combination ROC curve analyses of the 3 microRNAs as a means of distinguishing between patients with ALK-positive and ALK-negative NSCLC. ALK, anaplastic lymphoma kinase; AUC, area under the curve; NSCLC, non-small cell lung cancer; ROC, receiver operating characteristic curve. 

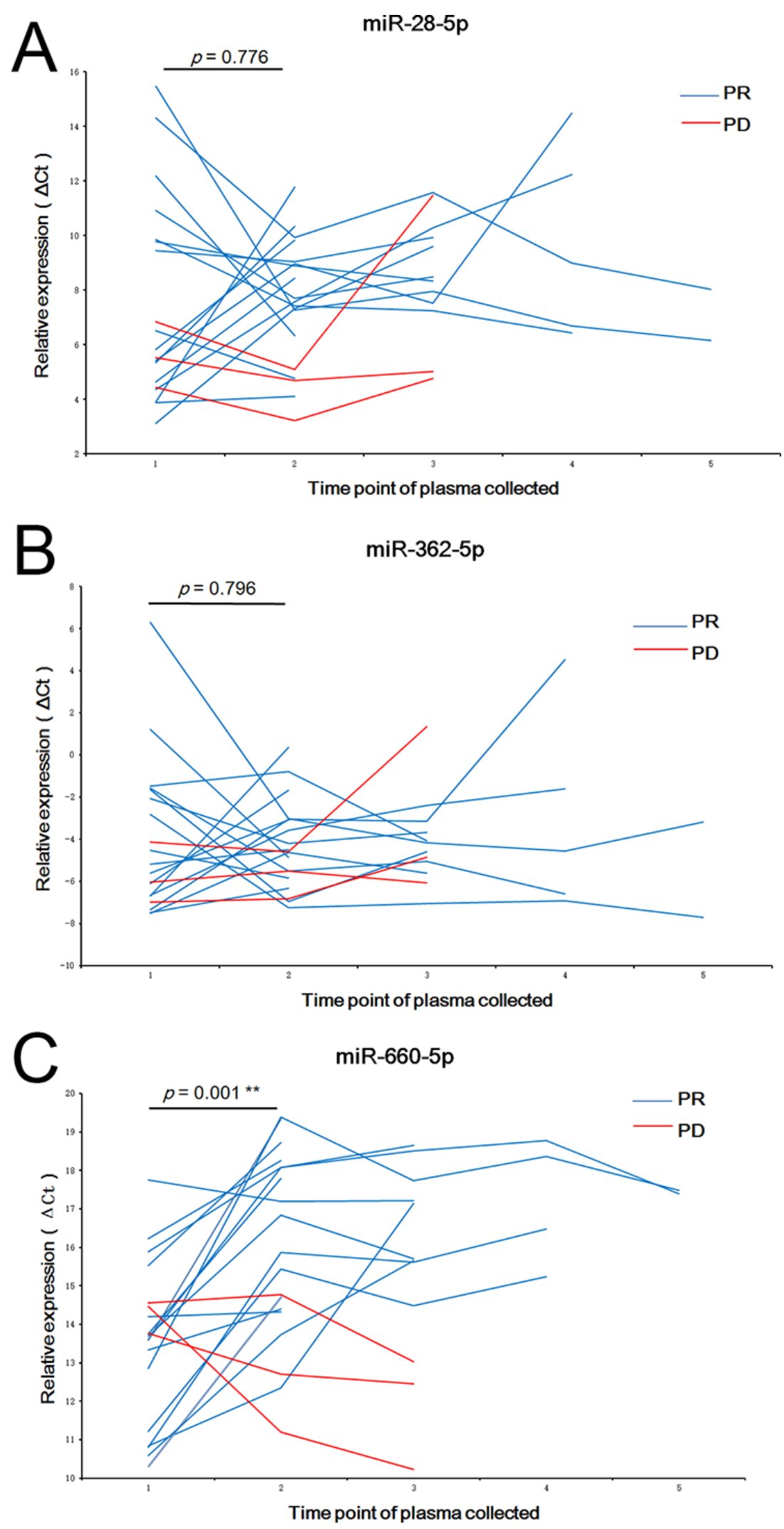

Figure 6: The changes of plasma levels of miR-28-5p, miR-362-5p, and miR-660-5p before and after treatment with crizotinib. The y-axes show the fold change of miR-28-5p (A) miR-362-5p (B) and miR-660-5p (C) which were normalized to 5s rRNA. 
would require investigating samples from multiple centers. Second, the number of participants was relatively small. Future work will require a larger number of samples to ensure the reliability of the 3-microRNA panel. Third, the present study failed to investigate and compare the expressions of identified microRNAs in plasma and tissue from the same individuals. Future studies will require pairs of plasma and tissue sample from the same individuals, to verify whether expression levels of microRNAs in plasma and tissue are consistent.

In conclusion, in this preliminary and exploratory study, we established a plasma microRNA panel that may serve as a novel, non-invasive biomarker for the diagnosis of ALK-positive NSCLC, and may provide considerable value as a predictor of tumor response to treatment with crizotinib.

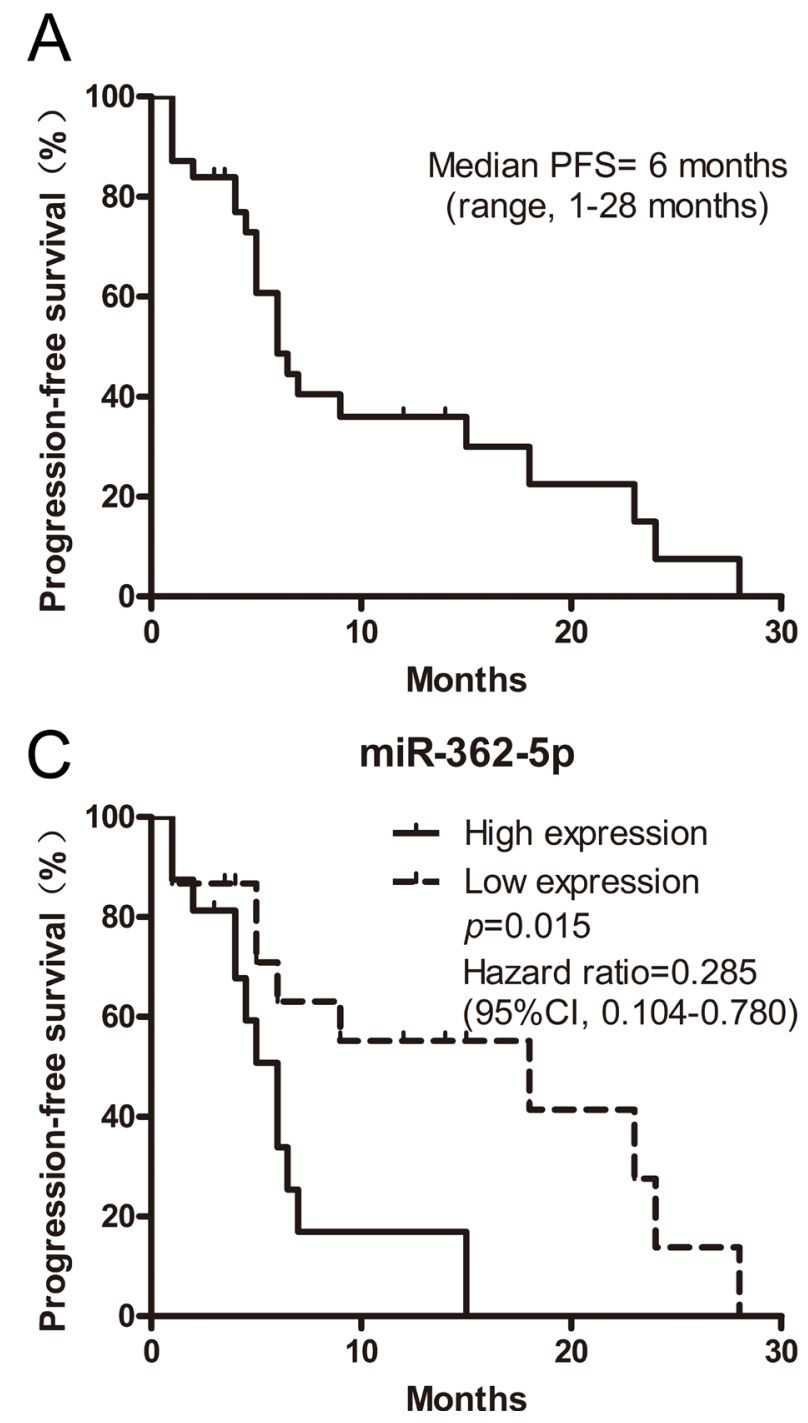

\section{MATERIALS AND METHODS}

\section{Participants and study design}

From December 2014 to August 2016, we enrolled a total of 116 participants from the Department of Lung Cancer and the Physical Examination Center at the Affiliated Hospital of Academy of Military Medical Science, including 91 patients with NSCLC, 6 patients with small cell lung cancer, 8 patients with benign lung disease, and 11 healthy subjects. Our study had a singlecenter, prospective, and clinical design. In the study cohort, the participants who had ALK-positive or ALK-negative NSCLC were consecutively enrolled, whereas the other participants were randomly enrolled. The inclusion criteria for ALK-positive NSCLC were (1) histological confirmed
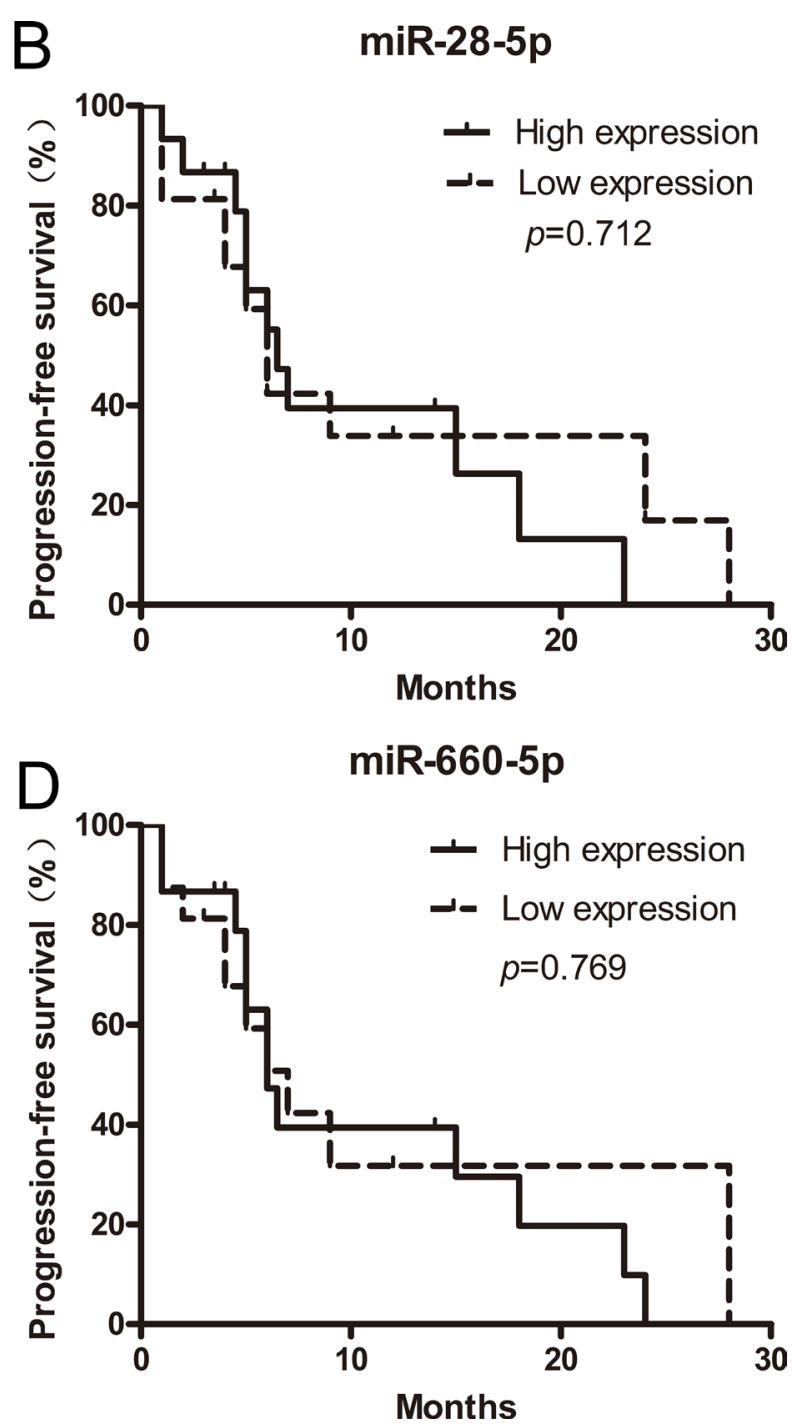

Figure 7: The relationship between the initial expression levels of plasma microRNAs and the progression-free survival (PFS) of ALK-positive patients receiving crizotinib $(\boldsymbol{n}=\mathbf{3 1})$. (A) PFS of ALK-positive patients who received crizotinib therapy. (B) PFS of ALK-positive patients, stratified according to the expression levels of miR-28-5p. (C) PFS of ALK-positive patients, stratified according to the expression levels of miR-362-5p. (D) PFS of ALK-positive patients, stratified according to the expression levels of miR-660-5p. All survival rates were estimated using the Kaplan-Meier method. 
advanced NSCLC, (2) age $\geq 18$ years, (3) expected survival more than 3 months, (4) ALK rearrangement measured by FISH before crizotinib, and (5) no history of ALK inhibitor therapy. Patients who had multiple tumors were excluded. All lung cancer patients were diagnosed by histopathological analysis. The clinical stage was assessed by 2 independent professional oncologists according to the American Joint Committee on Cancer (AJCC, 7th edition)/ Union for International Cancer Control (UICC) tumor, node, metastasis (TNM) staging system. Each lung cancer patient had a performance status within 0 to 1 , as evaluated according to the Eastern Cooperative Oncology Group (ECOG) criteria. Tumor assessments were performed at baseline and every 2 months during treatment until progression. Objective tumor response was evaluated following the Response Evaluation Criteria in Solid Tumors (RECIST). The healthy subjects were age- and gendermatched individuals who had no history of cancer and were in a condition of good health, based on the findings of physical examinations. In our study, patients with benign lung disease refer to patients with pneumonia who had been diagnosed by computed tomography scanning and bacteriological examination. This study was performed with the approval of the Affiliated Hospital of Academy of Military Medical Science Ethics Committee. Informed written consent was obtained from all patients/subjects.

To identify microRNAs that showed differential expression associated with ALK status, we first used microarray analysis in a discovery cohort consisting of 9 individuals: 3 ALK-positive NSCLC patients, 3 ALK-negative NSCLC patients, and 3 healthy subjects. Subsequently, RT-qPCR assays were used to identify the most stable circulating endogenous gene in 34 individuals $(8$ healthy subjects, 8 patients with benign lung disease, 6 patients with small cell lung cancer, 6 patients with squamous cell lung cancer, and 6 patients with adenocarcinoma lung cancer). Finally, we evaluated the plasma microRNAs by RT-qPCR assays from the validation cohort, which included 41 patients with ALKpositive NSCLC patients and 32 patients with ALKnegative NSCLC.

In addition, paired plasma samples were collected from 19 patients in the validation cohort before and after treatment with crizotinib. The plasma from these patients was analyzed using RT-qPCR to identify whether the microRNAs biomarkers were predictive of response to crizotinib. In the validation cohort, 41 patients were confirmed as having ALK-positive tumors at the initial diagnosis by FISH and 32 were ALK-negative. Of the 41 ALK-positive patients, 31 patients received treatment with crizotinib at an initial dose of $250 \mathrm{mg}$ twice daily, with appropriate dosing modification as needed. Of the 31 patients receiving crizotinib treatment, 19 had plasma samples taken at both the initial diagnosis and 2 months after treatment with crizotinib. The remaining 12 patients had plasma samples taken at the initial diagnosis only. The overall study design is shown in Figure 1. The characteristics of the 73 patients are summarized in Table 1.

\section{Plasma sample collection and RNA isolation}

For plasma collection, venous blood $(5 \mathrm{~mL})$ was collected and placed at room temperature for 1 hour, and then centrifuged at $1600 \mathrm{~g}$ for $10 \mathrm{~min}$ at $4^{\circ} \mathrm{C}$. The plasma was then divided into small aliquots and frozen at $-80^{\circ} \mathrm{C}$ until use. RNA was isolated from plasma using miRNeasy Mini Kit (Qiagen, Valencia, CA) following the manufacturer's protocol. In short, $200 \mu \mathrm{L}$ of EDTA-plasma were mixed with $1 \mathrm{~mL}$ of Qiazol Lysis Reagent, incubated for $5 \mathrm{~min}$ at room temperature, and subsequently mixed with $200 \mu \mathrm{L}$ of chloroform. The organic and aqueous phase was separated by centrifugation at $12,000 \mathrm{~g}$ for 15 min at $4^{\circ} \mathrm{C}$. The upper aqueous phase was collected and the RNA was precipitated by adding $100 \%$ ethanol. The mixture was applied to an miRNeasy Mini spin column. After washed several times, the RNA was eluted in $26 \mu \mathrm{L}$ of RNase-free water.

\section{MicroRNA microarray analysis}

The discovery cohort included plasma samples from 3 patients with ALK-positive lung cancer, 3 patients with ALK-negative lung cancer, and 3 healthy volunteers. These samples were analyzed by Agilent human microRNA microarray chips $\left(8^{*} 60 \mathrm{~K}\right), \mathrm{V} 21.0$. The data were extract via Agilent Feature Extraction Software (v10.7). Using the quantile algorithm in GeneSpring Software 12.6 (Agilent), the raw data were normalized. MicroRNAs with differential expression of 2-fold changes or more were sifted.

\section{Poly(A)-tailed RNA and reverse transcription}

According to methods reported previously [39], poly(A)-tailed RNAs were used in real-time reverse transcriptase polymerase chain reaction. In brief, total RNAs isolated from $100 \mu \mathrm{L}$ of plasma, $20 \mu \mathrm{M}$ of rATP, $1.5 \mu \mathrm{L}$ of poly(A) polymerase reaction buffer, and 1 unit poly(A) polymerase (New England Biolabs, Hitchin, UK) were mixed in a $15-\mu \mathrm{L}$ reaction system and incubated at $37^{\circ} \mathrm{C}$ for 60 min according to the manufacturer's protocol. Subsequently, poly(A)-tailed small RNA $(15-\mu \mathrm{L}$ total volume) was incubated with $2 \mu \mathrm{L}$ of reverse-transcriptase primer (5'-GCG AGC ACA GAA TTA ATA CGA CTC ACT ATA GG (T) $18\left(\mathrm{~A}, \mathrm{G}\right.$ or C)(A,G,C or T) $\left.-3^{\prime}\right)$ at $70^{\circ} \mathrm{C}$ for $5 \mathrm{~min}$ to remove any RNA secondary structure. The reactions were chilled on ice for at least $5 \mathrm{~min}$ and the remaining reagents, then $8 \mu \mathrm{L}$ of $5 \times$ ImProm- II reverse transcription buffer, $105 \mu \mathrm{mol}$ of $\mathrm{MgCl} 2,20 \mu \mathrm{mol}$ of dNTP, 40 units of RNAase inhibitor, and 30 units of ImProm- II reverse transcriptase (Promega, Madison, WI, USA), were added according to the protocol. The reaction 
system was $40 \mu \mathrm{L}$, proceeding at $42^{\circ} \mathrm{C}$ for $30 \mathrm{~min}, 72^{\circ} \mathrm{C}$ for $15 \mathrm{~min}$, and $20^{\circ} \mathrm{C}$ for $5 \mathrm{~min}$.

\section{Identification of the stable endogenous control}

Currently, there is no standard endogenous control for the circulating microRNA studies. Before the RTqPCR, we tried to find a stable endogenous control gene for circulating microRNAs of lung cancer patients and health subjects. Thirty-four blood samples were involved, including samples from 8 patients with benign lung disease, 8 healthy subjects, 6 patients with small cell lung cancer, 6 patients with squamous cell lung cancer, and 6 patients with adenocarcinoma lung cancer. The candidate internal reference genes were chosen based on a search of the literature. Twelve candidate genes were selected, including 5s rRNA, 18s rRNA, RNU6B, RNU38B, RNU44, RNU43, RNU48, miR-221-3p, miR-93-5p, miR-191-5p, miR-103-3p, and miR-197-3p. The stable (S) value calculated from NormFinder software and the $\mathrm{M}$ value calculated from geNorm software were used as a screening criterion. NormFinder ranks the microRNAs by calculating stability (S) values, whereas geNorm determines the expression stabilities of the microRNAs by calculating the minimum $\mathrm{M}$ value. The genes with an $\mathrm{S}$ value below the cut-off level of 0.5 from NormFinder and with the minimum $\mathrm{M}$ value from GeNorm were selected as stable candidates for further RT-qPCR evaluation.

\section{Real-time qRT-PCR}

RT-qPCR was used to measure the levels of 13 microRNAs that were differentially expressed according to microarray analysis: $\mathrm{miR}-362-5 \mathrm{p}$, miR-660-5p, miR340-5p, miR-28-5p, miR-579-5p, miR-96-5p, miR-19a-3p, miR-17-5p, miR-20a-5p, miR-24-3p, miR-107, miR-16-5p, and miR-22-3p. The primers of $5 \mathrm{~s}$ rRNA and the 13 microRNAs for RT-qPCR are listed in Table 3. The microRNA expression level was measured using the $\Delta \mathrm{Ct}$ method, in which the $\mathrm{Ct}$ threshold cycle is the fractional cycle number when the fluorescence of each sample passes a fixed threshold. The relative quantification of each microRNA was performed using the chosen, stable endogenous control gene as a references gene, which was validated before. The expression levels of selected microRNAs were normalized to $5 \mathrm{~s}$ rRNA. The results were expressed as $\triangle \mathrm{CT}\left(\mathrm{Ct}_{\text {miR }}-\mathrm{Ct}_{\text {ref }}\right)$ for each subject. The relative expression levels of microRNAs in plasma between patients with ALK-positive NSCLC and those with ALKnegative NSCLC were calculated using the $2^{-\Delta \Delta \mathrm{Ct}}$ method. The RT-qPCR was conducted on Agilent StrataGene Mx3000P Real-Time PCR System (Agilent Technologies, Germany) in 96 -well plates at $95^{\circ} \mathrm{C}$ for $15 \mathrm{~min}$, followed by 45 cycles of $94^{\circ} \mathrm{C}$ for $15 \mathrm{~s}, 56^{\circ} \mathrm{C}$ for $30 \mathrm{~s}$, and then $68^{\circ} \mathrm{C}$ for $30 \mathrm{~s}$. The specificity of polymerase chain reaction products was evaluated by the melting curve analysis.

\section{Statistical analysis}

The data were presented as means \pm standard errors of the means (SEMs) for microRNAs or as means \pm standard deviations (SDs) for other variables. Relative levels of 3 microRNAs were quantified using the $2^{-\Delta \Delta \mathrm{Ct}}$ method. Data were analyzed using 2-sided tests and a $p$ value $<0.05$ was considered statistically significant. Receiver operating characteristic (ROC) curve analyses were performed, and Youden's index was chosen to identify the optimal cut-off threshold values. The area under the ROC curve (AUC) was calculated to evaluate the specificity and sensitivity of predictions of ALK-positive NSCLC for each microRNA, as well as for the combination of microRNAs. PFS was measured from the start of crizotinib administration until the date of progressive disease, according to the RECIST. PFS was analyzed using the Kaplan-Meier method, and differences in survival were evaluated using the Logrank test. Multivariate regression analysis was conducted using the Cox proportional hazards model. These measures of diagnostic performance were estimated using GraphPad Prism 5.0 (GraphPad, La Jolla, CA, USA) and IBM SPSS 19.0 (IBM, Armonk, NY, USA) software. The selection of optimal reference genes was conducted using geNorm and NormFinder (Aarhus University Hospital, Aarhus, Denmark), as previously described $[40,41]$. The Wilcoxon matched pairs signed rank sum test was used to analyze the changes of plasma levels before and after crizotinib treatment.

\section{Abbreviations}

ALK, anaplastic lymphoma kinase; AUC, area under the curve; HS, healthy subjects; NPV, negative predictive value; NSCLC, non-small cell lung cancer; PPV, positive predictive value; ROC, receiver operating characteristic curve; RT-qPCR, real-time reverse transcriptase quantitative polymerase chain reaction; SD, standard deviation; SEM, standard error of the mean.

\section{Authors' contributions}

LLL designed the experiments and wrote the manuscript. LLL and LLQ performed the experiments and analyzed the data. HJF and XFZ provided experimental support. CHT, XYL, JC, WXW, SXY, and HFQ provided patient information and obtained consent from enrolled patients. LW, GHZ, PPL, MZ, and YYL collected the clinical samples. LLL prepared the figures. HW and HJG provided clinical support. XQL provided clinical and experimental support, and wrote the manuscript.

\section{ACKNOWLEDGMENTS}

We thank Dr. Dong Ke, Dr. Yuan Shen, and Dr. Jie Zhu for providing technical support. We thank Dr. Hai-Xu Hu for providing sample preservation. 


\section{CONFLICTS OF INTEREST}

We declare that no author has any financial or nonfinancial competing interest to disclose.

\section{FUNDING}

This work was supported by a grant from the Ministry of Science and Technology of the People's Republic of China (Chinese National Instrumentation Program, No. 2011YQ170067; URL of funder's website: www.most.gov.cn; XQL received the funding). The funders had no role in the study design, data collection, analysis, decision to publish, or preparation of the manuscript.

\section{REFERENCES}

1. Soda M, Choi YL, Enomoto M, Takada S, Yamashita Y, Ishikawa S, Fujiwara S, Watanabe $\mathrm{H}$, Kurashina $\mathrm{K}$, Hatanaka H, Bando M, Ohno S, Ishikawa Y, et al. Identification of the transforming EML4-ALK fusion gene in non-small-cell lung cancer. Nature. 2007; 448:561-6.

2. Shaw AT, Yeap BY, Mino-Kenudson M, Digumarthy SR, Costa DB, Heist RS, Solomon B, Stubbs H, Admane S, McDermott U, Settleman J, Kobayashi S, Mark EJ, et al. Clinical features and outcome of patients with non-smallcell lung cancer who harbor EML4-ALK. J Clin Oncol. 2009; 27:4247-53.

3. Kwak EL, Bang YJ, Camidge DR, Shaw AT, Solomon B, Maki RG, Ou SH, Dezube BJ, Janne PA, Costa DB, VarellaGarcia M, Kim WH, Lynch TJ, et al. Anaplastic lymphoma kinase inhibition in non-small-cell lung cancer. N Engl J Med. 2010; 363:1693-703.

4. Shaw AT, Kim DW, Nakagawa K, Seto T, Crino L, Ahn MJ, De Pas T, Besse B, Solomon BJ, Blackhall F, Wu YL, Thomas M, O’Byrne KJ, et al. Crizotinib versus chemotherapy in advanced ALK-positive lung cancer. N Engl J Med. 2013; 368:2385-94.

5. National Comprehensive Cancer Network. NCCN Clinical Practice Guidelines in Oncology: Non-small cell lung cancer, Version 2.2017. https://www.nccn.org/professionals/ physician_gls/pdf/nscl.pdf. Accessed October 26, 2016.

6. Swarup V, Rajeswari MR. Circulating (cell-free) nucleic acids--a promising, non-invasive tool for early detection of several human diseases. FEBS Lett. 2007; 581:795-9.

7. Fleischhacker M, Schmidt B. Circulating nucleic acids (CNAs) and cancer-a survey. Biochim Biophys Acta. 2007; 1775:181-232.

8. Tsang JC, Lo YM. Circulating nucleic acids in plasma/ serum. Pathology. 2007; 39:197-207.

9. Brase JC, Wuttig D, Kuner R, Sultmann H. Serum microRNAs as non-invasive biomarkers for cancer. Mol Cancer. 2010; 9:306.

10. Urquidi V, Netherton M, Gomes-Giacoia E, Serie D, Eckel-Passow J, Rosser CJ, Goodison S. Urinary mRNA biomarker panel for the detection of urothelial carcinoma. Oncotarget. 2016; 7:38731-40. https://doi.org/10.18632/ oncotarget.9587.

11. Kawaguchi $\mathrm{T}$, Komatsu $\mathrm{S}$, Ichikawa $\mathrm{D}$, Tsujiura $\mathrm{M}$, Takeshita H, Hirajima S, Miyamae M, Okajima W, Ohashi T, Imamura T, Kiuchi J, Konishi H, Shiozaki A, et al. Circulating MicroRNAs: A Next-Generation Clinical Biomarker for Digestive System Cancers. Int J Mol Sci. 2016; 17:1459.

12. Slaby O. Non-coding RNAs as Biomarkers for Colorectal Cancer Screening and Early Detection. Adv Exp Med Biol. 2016; 937:153-70.

13. Zhi F, Shao N, Li B, Xue L, Deng D, Xu Y, Lan Q, Peng Y, Yang Y. A serum 6-miRNA panel as a novel non-invasive biomarker for meningioma. Sci Rep. 2016; 6: 32067.

14. Imaoka H, Toiyama Y, Fujikawa H, Hiro J, Saigusa S, Tanaka K, Inoue Y, Mohri Y, Mori T, Kato T, Toden S, Goel A, Kusunoki M. Circulating microRNA-1290 as a novel diagnostic and prognostic biomarker in human colorectal cancer. Ann Oncol. 2016; 27:1879-86.

15. Zhu W, He J, Chen D, Zhang B, Xu L, Ma H, Liu X, Zhang Y, Le H. Expression of miR-29c, miR-93, and miR-429 as potential biomarkers for detection of early stage nonsmall lung cancer. PLoS One. 2014; 9: e87780.

16. Keller A, Leidinger P, Gislefoss R, Haugen A, Langseth H, Staehler P, Lenhof HP, Meese E. Stable serum miRNA profiles as potential tool for non-invasive lung cancer diagnosis. RNA Biol. 2011; 8:506-16.

17. Bartel DP. MicroRNAs: genomics, biogenesis, mechanism, and function. Cell. 2004; 116:281-97.

18. He L, Hannon GJ. MicroRNAs: small RNAs with a big role in gene regulation. Nat Rev Genet. 2004; 5:522-31.

19. Ambros V. The functions of animal microRNAs. Nature. 2004; 431:350-5.

20. Esquela-Kerscher A, Slack FJ. Oncomirs - microRNAs with a role in cancer. Nat Rev Cancer. 2006; 6:259-69.

21. Calin GA, Croce CM. MicroRNA signatures in human cancers. Nat Rev Cancer. 2006; 6:857-66.

22. Ryan BM, Robles AI, Harris CC. Genetic variation in microRNA networks: the implications for cancer research. Nat Rev Cancer. 2010; 10:389-402.

23. Chen X, Ba Y, Ma L, Cai X, Yin Y, Wang K, Guo J, Zhang Y, Chen J, Guo X, Li Q, Li X, Wang W, et al. Characterization of microRNAs in serum: a novel class of biomarkers for diagnosis of cancer and other diseases. Cell Res. 2008; 18:997-1006.

24. Mitchell PS, Parkin RK, Kroh EM, Fritz BR, Wyman SK, Pogosova-Agadjanyan EL, Peterson A, Noteboom J, O'Briant KC, Allen A, Lin DW, Urban N, Drescher CW, et al. Circulating microRNAs as stable blood-based markers for cancer detection. Proc Natl Acad Sci USA. 2008; 105:10513-8.

25. Gasparini P, Cascione L, Landi L, Carasi S, Lovat F, Tibaldi C, Ali G, D'Incecco A, Minuti G, Chella A, Fontanini G, Fassan M, Cappuzzo F, et al. microRNA 
classifiers are powerful diagnostic/prognostic tools in ALK-, EGFR-, and KRAS-driven lung cancers. Proc Natl Acad Sci USA. 2015; 112:14924-9.

26. Almeida MI, Nicoloso MS, Zeng L, Ivan C, Spizzo R, Gafa R, Xiao L, Zhang X, Vannini I, Fanini F, Fabbri M, Lanza G, Reis RM, et al. Strand-specific miR-28-5p and miR-28-3p have distinct effects in colorectal cancer cells. Gastroenterology. 2012; 142:886-96.e9.

27. Lim EL, Trinh DL, Scott DW, Chu A, Krzywinski M, Zhao Y, Robertson AG, Mungall AJ, Schein J, Boyle M, Mottok A, Ennishi D, Johnson NA, et al. Comprehensive miRNA sequence analysis reveals survival differences in diffuse large B-cell lymphoma patients. Genome Biol. $2015 ; 16: 18$.

28. Wang C, Hu J, Lu M, Gu H, Zhou X, Chen X, Zen K, Zhang CY, Zhang T, Ge J, Wang J, Zhang C. A panel of five serum miRNAs as a potential diagnostic tool for early-stage renal cell carcinoma. Sci Rep. 2015; 5:7610.

29. Chen L, Jin Y, Wang L, Sun F, Yang X, Shi M, Zhan C, Shi Y, Wang Q. Identification of reference genes and miRNAs for qRT-PCR in human esophageal squamous cell carcinoma. Med Oncol. 2017; 34:2.

30. Choi YC, Yoon S, Byun Y, Lee G, Kee H, Jeong Y, Yoon J, Baek K. MicroRNA library screening identifies growthsuppressive microRNAs that regulate genes involved in cell cycle progression and apoptosis. Exp Cell Res. 2015; 339:320-32.

31. Girardot M, Pecquet C, Boukour S, Knoops L, Ferrant A, Vainchenker W, Giraudier S, Constantinescu SN. miR-28 is a thrombopoietin receptor targeting microRNA detected in a fraction of myeloproliferative neoplasm patient platelets. Blood. 2010; 116:437-45.

32. Hell MP, Thoma CR, Fankhauser N, Christinat Y, Weber TC, Krek W. miR-28-5p promotes chromosomal instability in VHL-associated cancers by inhibiting Mad2 translation. Cancer Res. 2014; 74:2432-43.

33. Sayagués JM, Corchete LA, Gutiérrez ML, Sarasquete ME, Del Mar Abad M, Bengoechea O, Fermiñán E, Anduaga MF, Del Carmen S, Iglesias M, Esteban C, Angoso M, Alcazar
JA, et al. Genomic characterization of liver metastases from colorectal cancer patients. Oncotarget. 2016; 7:72908-22. https://doi.org/10.18632/oncotarget.12140.

34. Vychytilova-Faltejskova P, Pesta M, Radova L, Liska V, Daum O, Kala Z, Svoboda M, Kiss I, Slaby O. Genomewide microRNA Expression Profiling in Primary Tumors and Matched Liver Metastasis of Patients with Colorectal Cancer. Cancer Genomics Proteomics. 2016; 13:311-6.

35. Li J, Song L, Zhou L, Wu J, Sheng C, Chen H, Liu Y, Gao S, Huang W. A MicroRNA Signature in Gestational Diabetes Mellitus Associated with Risk of Macrosomia. Cell Physiol Biochem. 2015; 37:243-52.

36. Wu K, Yang L, Chen J, Zhao H, Wang J, Xu S, Huang Z. miR-362-5p inhibits proliferation and migration of neuroblastoma cells by targeting phosphatidylinositol 3-kinase-C2beta. FEBS Lett. 2015; 589:1911-9.

37. Krishnan P, Ghosh S, Wang B, Li D, Narasimhan A, Berendt R, Graham K, Mackey JR, Kovalchuk O, Damaraju S. Next generation sequencing profiling identifies miR-574-3p and miR-660-5p as potential novel prognostic markers for breast cancer. BMC Genomics. 2015; 16:735.

38. Paydas S, Acikalin A, Ergin M, Celik H, Yavuz B, Tanriverdi K. Micro-RNA (miRNA) profile in Hodgkin lymphoma: association between clinical and pathological variables. Med Oncol. 2016; 33: 34.

39. Fu HJ, Zhu J, Yang M, Zhang ZY, Tie Y, Jiang H, Sun ZX, Zheng XF. A novel method to monitor the expression of microRNAs. Mol Biotechnol. 2006; 32:197-204.

40. Vandesompele J, De Preter K, Pattyn F, Poppe B, Van Roy N, De Paepe A, Speleman F. Accurate normalization of real-time quantitative RT-PCR data by geometric averaging of multiple internal control genes. Genome Biol. 2002; 3: Research0034.1-.11.

41. Andersen CL, Jensen JL, Orntoft TF. Normalization of realtime quantitative reverse transcription-PCR data: a modelbased variance estimation approach to identify genes suited for normalization, applied to bladder and colon cancer data sets. Cancer Res. 2004; 64:5245-50. 